\title{
Solution of Wave Equation in Radial Form by VIM
}

\author{
Hossein Aminikhah \\ Department of Applied Mathematics, School of Mathematical Sciences, University of Guilan, P.O. Box 1914, Rasht 41938, Iran
}

Correspondence should be addressed to Hossein Aminikhah, hossein.aminikhah@gmail.com

Received 23 December 2011; Accepted 1 February 2012

Academic Editors: G. Bella and E. Weber

Copyright (C) 2012 Hossein Aminikhah. This is an open access article distributed under the Creative Commons Attribution License, which permits unrestricted use, distribution, and reproduction in any medium, provided the original work is properly cited.

An analytic approximation to the solution of wave equation is studied. Wave equation is in radial form with indicated initial and boundary conditions, by variational iteration method it has been used to derive this approximation and some examples are presented to show the simplicity and efficiency of the method.

\section{Introduction}

Wave equation has attracted much attention and solving these kind of equations has been one of the interesting tasks for mathematicians. Variational iteration method is known as a powerful device for solving functional equations [17]. Numerical methods which are commonly used as finitedifference methods and characteristics method need large size of computational works and usually the effect of roundoff error causes the loss of accuracy in the results. Analytical methods commonly used for solving wave equation are very restricted and can be used in special cases, so they cannot be used to solve equations resulted by mathematical modeling of numerous realistic scenarios. In this article, the variational iteration method has been applied to solve more general forms of wave equation.

\section{He's Variational Iteration Method}

The variational iteration method [8-13], which is a modified of general Lagrange multiplier method [14], has been shown to solve effectively, easily, and accurately large class of nonlinear problems with approximations which converge rapidly to accurate solutions. To illustrate the method, consider the following nonlinear equation:

$$
L u(t)+N u(t)=g(t)
$$

where $L$ is a linear operator, $N$ is a nonlinear operator, and $g(t)$ is a known analytic function. According to the variational iteration method, we can construct the following correction functional:

$$
u_{n+1}(t)=u_{n}(t)+\int_{0}^{t} \lambda(\xi)\left(L u_{n}(\xi)+N u_{n}(\xi)-g(\xi)\right) d \xi,
$$

where $\lambda$ is general Lagrange multiplier which can be identified via variational theory, $u_{0}(t)$ is an initial approximation with possible unknowns, and $\widetilde{u}_{n}$ is considered as restricted variation [15] (i.e., $\delta \tilde{u}_{n}=0$ ). Therefore, we first determine the Lagrange multiplier $\lambda$ that will be identified optimally via integration by parts. The successive approximations $u_{n+1}(t)$ of the solution $u(t)$ will be readily obtained upon using the obtained Lagrange multiplier and by using any selective function $u_{0}$. Consequently, the exact solution may be obtained by $u=\lim _{n \rightarrow \infty} u_{n}$.

\section{Numerical Results}

To illustrate the method and to show ability of the method, some examples are presented.

Example 1. Let us have one-dimensional wave equation in radial form with initial condition:

$$
\begin{gathered}
\frac{\partial^{2} u}{\partial t^{2}}=\frac{\partial^{2} u}{\partial r^{2}}+\frac{1}{r} \frac{\partial u}{\partial r} \\
u\left(r_{i}, 0\right)=r .
\end{gathered}
$$


Its correction functional can be expressed as follows:

$$
\begin{aligned}
u_{n+1}(r, t)= & u_{n}(r, t) \\
& +\int_{0}^{t}(\xi-t)\left(\frac{\partial^{2} u_{n}}{\partial \xi^{2}}-\frac{\partial^{2} \tilde{u}_{n}}{\partial r^{2}}-\frac{1}{r} \frac{\partial \tilde{u}_{n}}{\partial r}\right) d \xi
\end{aligned}
$$

To make this correct functional stationary, $\delta u_{n}(r, 0)=0$,

$$
\begin{aligned}
\delta u_{n+1}= & \delta u_{n}+\left(\lambda_{1}\left(\delta u_{n}\right)^{\prime}\right)_{0}^{t}-\left(\lambda_{1}^{\prime} \delta u_{n}\right)_{0}^{t} \\
& +\int_{0}^{t} \lambda_{1}^{\prime \prime} \delta u_{n} d \xi=0
\end{aligned}
$$

Its stationary conditions can be obtained as follows:

$$
\begin{gathered}
\delta u_{n}: 1-\lambda_{1}^{\prime}(t)=0, \\
\delta u_{n}^{\prime}: \lambda_{1}(t)=0, \\
\delta u_{n}: \lambda_{1}^{\prime \prime}(\xi)=0,
\end{gathered}
$$

from which Lagrange multiplier can be identified as $\lambda_{1}=\xi-$ $t$, and the following iteration formula will be obtained:

$$
\begin{aligned}
u_{n+1}(r, t)= & u_{n}(r, t) \\
& +\int_{0}^{t}(\xi-t)\left(\frac{\partial^{2} u_{n}}{\partial \xi^{2}}-\frac{\partial^{2} u_{n}}{\partial r^{2}}-\frac{1}{r} \frac{\partial u_{n}}{\partial r}\right) d \xi
\end{aligned}
$$

Beginning with $u_{0}(r, t)=r$, by iteration formula (7), we have

$$
\begin{gathered}
u_{1}(r, t)=r+\frac{1}{2 ! r} t^{2}, \\
u_{2}(r, t)=r+\frac{1}{2 ! r} t^{2}+\frac{1^{2}}{4 ! r^{3}} t^{4} \\
u_{3}(r, t)=r+\frac{1}{2 ! r} t^{2}+\frac{1^{2}}{4 ! r^{3}} t^{4}+\frac{1^{2} \times 3^{2}}{6 ! \times r^{5}} t^{6}, \\
\vdots
\end{gathered}
$$

from which the general term and so the solution will be determined as follows:

$$
u(r, t)=r+\sum_{n=1}^{\infty} \frac{1^{2} \times 3^{2} \times \cdots \times(2 n-3)^{2}}{(2 n) ! r^{2 n-1}} t^{2 n} .
$$

Example 2. Let us solve two-dimensional wave equation in radial form with the boundary conditions:

$$
\begin{gathered}
\frac{\partial^{2} u}{\partial t^{2}}=\frac{\partial^{2} u}{\partial r^{2}}+\frac{1}{r} \frac{\partial u}{\partial r}+\frac{1}{r^{2}} \frac{\partial^{2} u}{\partial \theta^{2}} \\
u_{r}(1, \theta, t)=-1, \quad u_{r}(10, \theta, t)=0, \quad u_{\theta}(r, 1, t)=1 .
\end{gathered}
$$

Its correction functional can be expressed as follows:

$$
\begin{aligned}
u_{n+1}(r, \theta, t)= & u_{n}(r, \theta, t) \\
& +\int_{1}^{r} \lambda_{2}\left(\frac{\partial^{2} u_{n}}{\partial \xi^{2}}+\frac{1}{\xi} \frac{\partial u_{n}}{\partial \xi}+\frac{1}{\xi^{2}} \frac{\partial \tilde{u}_{n}}{\partial \theta^{2}}-\frac{\partial^{2} \tilde{u}_{n}}{\partial t^{2}}\right) d \xi
\end{aligned}
$$

Making the above correct functional stationary, notice that $\delta u_{n}(1, \theta, t)=0$ :

$$
\begin{aligned}
\delta u_{n+1}= & \delta u_{n}+\left(\lambda_{2}\left(\delta u_{n}\right)^{\prime}\right)_{1}^{r}-\left(\lambda_{2}^{\prime} \delta u_{n}\right)_{1}^{r} \\
& +\int_{1}^{r} \lambda_{2}^{\prime \prime} \delta u_{n} d \xi+\left(\frac{\lambda_{2}}{\xi} \delta u_{n}\right)_{1}^{r} \\
& -\int_{1}^{r} \frac{\xi \lambda_{2}^{\prime}-\lambda_{2}}{\xi^{2}} \delta u_{n} d \xi=0 .
\end{aligned}
$$

Its stationary conditions can be obtained as follows:

$$
\begin{gathered}
\delta u_{n}: \lambda_{2}^{\prime \prime}-\frac{\xi \lambda_{2}^{\prime}-\lambda_{2}}{\xi^{2}}=0, \\
\delta u_{n}^{\prime}: \lambda_{2}(r)=0, \\
\delta u_{n}: 1-\lambda_{2}^{\prime}(r)+\frac{\lambda_{2}(r)}{r}=0,
\end{gathered}
$$

from which the Lagrange multiplier would be identified as follows:

$$
\lambda_{2}(\xi)=\xi(\ln \xi-\ln r) .
$$

Substituting (14) into (11) leads to the following iteration formula:

$$
\begin{aligned}
u_{n+1}(r, \theta, t)= & u_{n}(r, \theta, t) \\
& +\int_{1}^{r} \xi(\ln \xi-\ln r)\left(\frac{\partial^{2} u_{n}}{\partial \xi^{2}}+\frac{1}{\xi} \frac{\partial u_{n}}{\partial \xi}\right. \\
& \left.+\frac{1}{\xi^{2}} \frac{\partial u_{n}}{\partial \theta^{2}}-\frac{\partial^{2} u_{n}}{\partial t^{2}}\right) d \xi .
\end{aligned}
$$

Starting with

$$
u_{0}(r, \theta, t)=A r^{2}+B \theta^{2}+C t^{2}
$$

we have

$$
\begin{aligned}
u_{1}(r, \theta, t)= & A r^{2}+B \theta^{2}+C t^{2} \\
& +\int_{1}^{r} \xi(\ln \xi-\ln r)\left(4 A+\frac{2}{\xi^{2}} B-2 C\right) d \xi \\
= & A(1+2 \ln r)+B\left(\theta^{2}-(\ln r)^{2}\right) \\
& +C\left(t^{2}+\frac{r^{2}}{2}-\frac{1}{2}-\ln r\right) .
\end{aligned}
$$

Imposing the boundary conditions yields to $A=-1 / 2, B=$ $1, C=1+\ln 10 / 99$.

Thus, we have

$$
\begin{aligned}
u_{1}(r, \theta, t)=\frac{1}{198} & \left(-100-\ln 10+(1+\ln 10) r^{2}-99(\ln r)^{2}\right. \\
& -(200+2 \ln 10) \ln r+99 \theta^{2} \\
& \left.+2(1+\ln 10) t^{2}\right)
\end{aligned}
$$

which is an exact solution. 
Example 3. Consider Example 1 with boundary conditions following:

$$
u(1, t)=1, \quad u_{r}(1, t)=t
$$

Similar to Example 2, the Lagrange multiplier can be identified as $\lambda_{3}(\xi)=\xi(\ln \xi-\ln r)$ and the following iteration formula will be obtained:

$$
\begin{aligned}
u_{n+1}(r, t)= & u_{n}(r, t) \\
& +\int_{1}^{r} \xi(\ln \xi-\ln r)\left(\frac{\partial^{2} u_{n}}{\partial \xi^{2}}+\frac{1}{\xi} \frac{\partial u_{n}}{\partial \xi}-\frac{\partial^{2} u_{n}}{\partial t^{2}}\right) d \xi .
\end{aligned}
$$

Starting with

$$
u_{0}(r, t)=r+\int_{1}^{r} t d \xi=1+t(r-1)
$$

by iteration formula (20), we have

$$
u_{1}(r, t)=1+t \ln r
$$

which is an exact solution.

\section{Conclusion}

In this work, we present an analytical approximation to the solution of wave equation in radial form in different cases. We have achieved this goal by applying variational iteration method. The small size of computations in comparison with the computational size required in numerical methods and the rapid convergence shows that the variational iteration method is reliable and introduces a significant improvement in solving the wave equation over existing methods. The main advantage of the VIM over A.D.M. is that this method provides the solution without a need for calculating Adomian's polynomials [16].

\section{References}

[1] A. Yildirim, S. T. Mohyud-Din, and D. H. Zhang, "Analytical solutions to the pulsed Klein-Gordon equation using Modified Variational Iteration Method (MVIM) and Boubaker Polynomials Expansion Scheme (BPES)," Computers and Mathematics with Applications, vol. 59, no. 8, pp. 2473-2477, 2010.

[2] A. Yildirim and T. Öziş, "Solutions of singular IVPs of LaneEmden type by the variational iteration method," Nonlinear Analysis, Theory, Methods and Applications, vol. 70, no. 6, pp. 2480-2484, 2009.

[3] S. Momani and S. Abuasad, "Application of He's variational iteration method to Helmholtz equation," Chaos, Solitons and Fractals, vol. 27, no. 5, pp. 1119-1123, 2006.

[4] M. A. Abdou and A. A. Soliman, "Variational iteration method for solving Burger's and coupled Burger's equations," Journal of Computational and Applied Mathematics, vol. 181, no. 2, pp. 245-251, 2005.

[5] J. Biazar and H. Ghazvini, "He's variational iteration method for fourth-order parabolic equations," Computers and Mathematics with Applications, vol. 54, no. 7-8, pp. 1047-1054, 2007.
[6] J. Biazar and H. Ghazvini, "He's variational iteration method for solving hyperbolic differential equations," International Journal of Nonlinear Sciences and Numerical Simulation, vol. 8, no. 3, pp. 311-314, 2007.

[7] J. Biazar and H. Ghazvini, "He's variational iteration method for solving linear and non-linear systems of ordinary differential equations," Applied Mathematics and Computation, vol. 191, no. 1, pp. 287-297, 2007.

[8] J. H. He, "Some asymptotic methods for strongly nonlinear equations," International Journal of Modern Physics B, vol. 20, no. 10, pp. 1141-1199, 2006.

[9] J. H. He, "Approximate analytical solution for seepage flow with fractional derivatives in porous media," Computer Methods in Applied Mechanics and Engineering, vol. 167, no. 1-2, pp. 57-68, 1998.

[10] J. H. He, "Variational iteration method for autonomous ordinary differential systems," Applied Mathematics and Computation, vol. 114, no. 2-3, pp. 115-123, 2000.

[11] J. He, "A new approach to nonlinear partial differential equations," Communications in Nonlinear Science and Numerical Simulation, vol. 2, no. 4, pp. 230-235, 1997.

[12] J. H. He, "A variational iteration approach to nonlinear problems and its applications," Mechanical Application, vol. 20, no. 1, pp. 30-31, 1998.

[13] J. H. He, "Variational iteration method-a kind of non-linear analytical technique: some examples," International Journal of Non-Linear Mechanics, vol. 34, no. 4, pp. 699-708, 1999.

[14] M. Inokuti et al., "General use of the Lagrange multiplier in nonlinear mathematical physics," in Variational Method in the Mechanics of Solids Pergamon Press, S. N. Nasser, Ed., pp. 156162, 1978.

[15] B. A. Finlayson, The Method of Weighted Residuals and Variational Principles, Academic Press, 1972.

[16] J. Biazar and R. Islam, "Solution of wave equation by Adomian decomposition method and the restrictions of the method," Applied Mathematics and Computation, vol. 149, no. 3, pp. 807-814, 2004. 


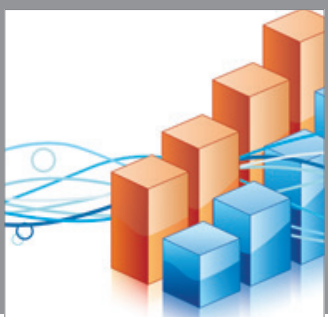

Advances in

Operations Research

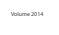

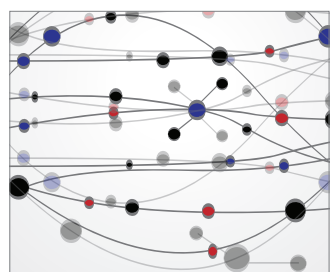

\section{The Scientific} World Journal
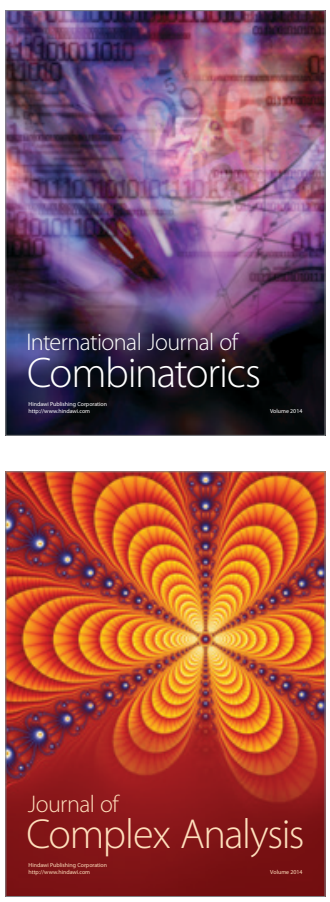

International Journal of

Mathematics and

Mathematical

Sciences
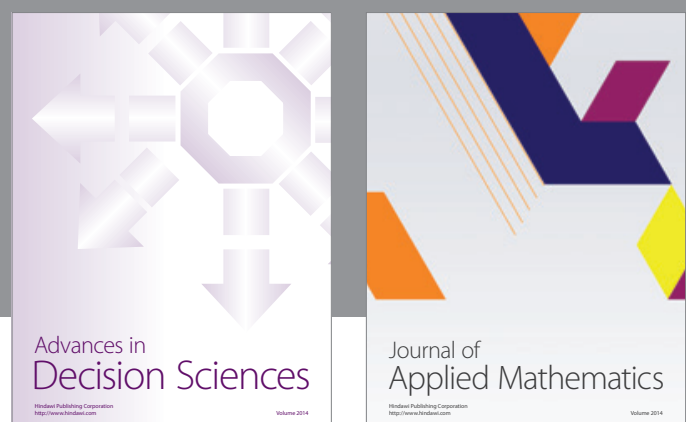

Journal of

Applied Mathematics
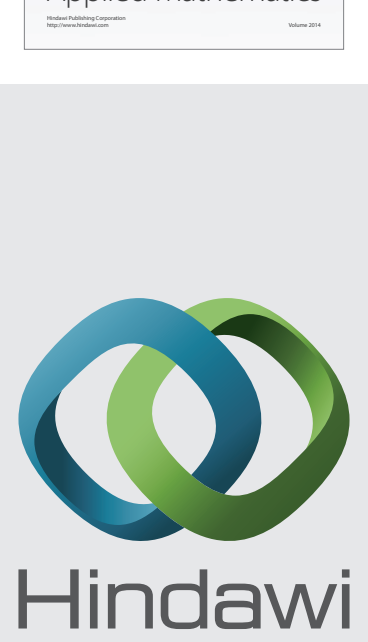

Submit your manuscripts at http://www.hindawi.com
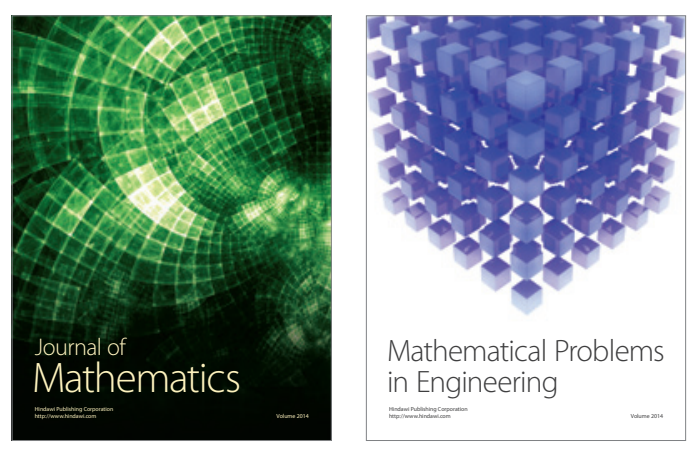

Mathematical Problems in Engineering
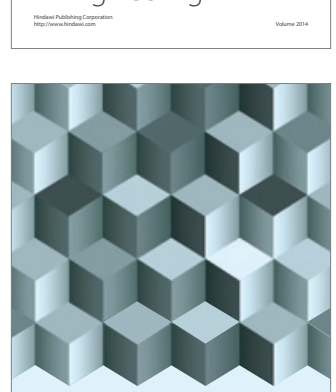

Journal of

Function Spaces
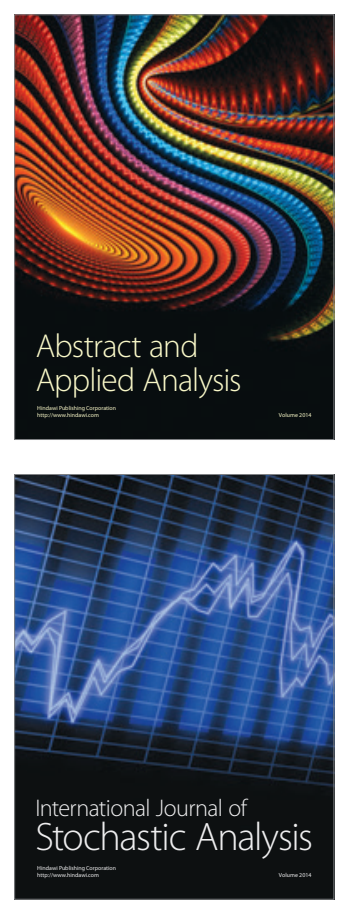

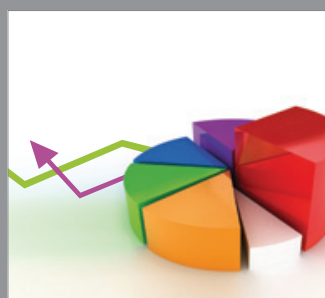

ournal of

Probability and Statistics

Promensencen
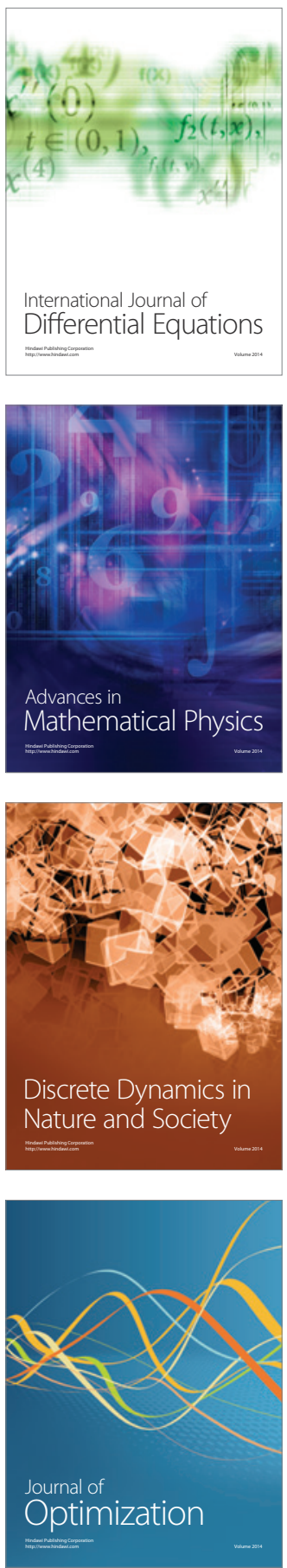